\title{
Egg survival is reduced by grave-soil microbes in the carrion beetle, Nicrophorus vespilloides
}

\author{
Chris G C Jacobs ${ }^{1{ }^{* \dagger}}$, Yin Wang ${ }^{1 \dagger}$, Heiko Vogel ${ }^{2}$, Andreas Vilcinskas ${ }^{3}$, Maurijn van der Zee ${ }^{1}$ and Daniel E Rozen ${ }^{1 *}$
}

\begin{abstract}
Background: Nicrophorus vespilloides eggs are deposited into the soil in close proximity to the decomposing vertebrate carcasses that these insects use as an obligate resource to rear their offspring. Eggs in this environment potentially face significant risks from the bacteria that proliferate in the grave-soil environment following nutrient influx from the decomposing carcass. Our aims in this paper are twofold: first, to examine the fitness effects of grave-soil bacteria to eggs, and second, to quantify egg immunocompetence as a defence against these bacteria.

Results: Our results provide strong evidence that grave-soil microbes significantly reduce the survival of Nicrophorus eggs. Females provided with microbe rich carcasses to rear broods laid fewer eggs that were less likely to hatch than females given uncontaminated carcasses. Furthermore, we show that egg hatch success is significantly reduced by bacterial exposure. Using a split-brood design, which controlled for intrinsic differences in eggs produced by different females, we found that eggs washed free of surface-associated bacteria show increased survival compared to unwashed eggs. By contrast, eggs exposed to the entomopathogen Serratia marcescens show decreased survival compared to unexposed eggs. We next tested the immune competence of eggs under challenge from bacterial infection, and found that eggs lacked endogenous production of antimicrobial peptides, despite well-developed responses in larvae. Finally, we found that despite lacking immunity, N. vespilloides eggs produce an extraembryonic serosa, indicating that the serosa has lost its immune inducing capacity in this species.

Conclusions: The dependency on ephemeral resources might strongly select for fast developing animals. Our results suggest that Nicrophorus carrion beetles, and other species developing on ephemeral resources, face a fundamental trade-off between egg immunity and development time.
\end{abstract}

Keywords: Trade-off, Burying beetle, Egg immunity, Developmental speed

\section{Background}

Exposure to harmful microbes poses numerous and diverse threats to developing animals [1]. For animals with internal development, microbial pathogens that can directly harm the embryo can be controlled by the surveillance of maternal adaptive and innate immunity [2,3]. By contrast, microbial defence in animals that develop externally is provided by barrier protection from the egg surface, from maternally provided antimicrobials or through intrinsic immunity coordinated by the developing embryo [4]. These modes of protection have been

\footnotetext{
*Correspondence: c.g.c.jacobs@biology.leidenuniv.nl;

d.e.rozen@biology.leidenuniv.nl

${ }^{\dagger}$ Equal contributors

'Institute of Biology Leiden, Leiden University, Sylviusweg 72, 2333 Leiden,

$\mathrm{BE}$, the Netherlands

Full list of author information is available at the end of the article
}

extensively examined in vertebrates [5]. For example, avian egg shells provide direct physical protection against external microbial challenge, while mothers provision eggs prior to laying with a suite of general and specific antimicrobials, such as lysozyme, avidin and ovotransferrin [6], which provide crucial protection to the embryo prior to the maturation of the embryonic immune response. In invertebrates, parents can similarly invest in offspring defence via trans-generational immunity that provides diverse defences against pathogens and parasites that parents have encountered and which may pose specific threats to offspring [7]. This can occur via deposition of antimicrobials onto the insect egg surface, or maternal provisioning of antimicrobials into the egg itself [8-13]. In addition, embryos in some invertebrate species can also mount endogenous defences against pathogen challenge by producing antimicrobial peptides within 
eggs $[9,14,15]$. However, this response is not universal and is notably absent in the well-studied model species Drosophila [15].

Here we examine the role of egg immunity in the burying beetle Nicrophorus vespilloides. This species is particularly suited for this investigation because eggs of this species face considerable challenge from the bacteria they encounter during development [16]. Nicrophorus species reproduce on small vertebrate cadavers which they bury in the soil after they are located through volatiles emitted from the carcass. Burying beetle eggs are laid into the soil adjacent to vertebrate carcasses [17]. After a two-three day incubation, eggs hatch and larvae migrate to the carcass where they are communally reared by one or both parents [18]. Caring parents regurgitate food to their developing larvae and also provide protection against insect competitors and predators $[17,19]$. In addition, parents protect offspring against bacterial competitors growing on the decomposing carcass by depositing antimicrobial secretions, e.g. lysozyme, on the carcass surface [16,20-23]. Parental lysozyme secretion peaks during brood rearing and significantly increases larval survival [20]. Larvae also contribute to brood social immunity by secreting antimicrobials that inhibit bacterial growth $[24,25]$. They also show a progressive increase in humoral and cellular immunity through development [26]. Although different life stages of the burying beetle show both behavioural and immunological responses to reduce the negative effects of microbial challenge, studies of these responses to date have focussed on post-hatch behaviours and reductions in fitness $[16,27,28]$. However, pre-hatch reductions in fitness as a consequence of microbial exposure have not been studied; therefore, it remains unknown how or if eggs respond to the adverse environment in which they are laid.

In this study we investigated both the impact of soilborne bacteria on egg development and the ability of the eggs to mount immune responses. We first measured the consequences of microbial challenge on pre-hatch fitness by assessing egg survival across contrasting environmental conditions. Next, we tested whether antimicrobial peptide genes are expressed in burying beetle eggs in response to infection [29]. Briefly, we show that eggs are significantly harmed by exposure to microbes in grave soil and that eggs lack endogenous immunity. We discuss this lack of an immune response in the light of a tradeoff with developmental speed.

\section{Methods}

\section{General procedures}

Experimental animals were taken from an outbred laboratory population derived from wild-caught $N$. vespilloides individuals trapped in Warmond near Leiden in The Netherlands, between May and June 2013. Beetles were maintained in the laboratory at $20^{\circ} \mathrm{C}$ with a $15: 9$ hour light:dark cycle. All adults were fed fresh chicken liver twice weekly. To collect eggs, non-sibling pairs of beetles were allowed to mate for 24 hours, after which the female was removed and provided with either a Fresh or Aged mouse carcass weighing 24-26 g in a $15 \mathrm{~cm} \times 10 \mathrm{~cm}$ plastic box filled with approximately $1-2 \mathrm{~cm}$ of soil. The state of found carcasses in the field across the breeding season remains unclear. Accordingly our treatments are meant to represent different extremes of the potential continuum of carcass decay. Following [16], Fresh carcasses are defined as mice that were thawed after removal from the freezer and provided directly to mated females, while Aged carcasses were allowed to age for 7 days on top of commercial peat soil before mated females were added.

\section{Egg survival}

Mated females were provided with either a Fresh $(n=35)$ or Aged $(n=35)$ carcass in order to quantify the role of carcass age on egg number and survival. Commencing the morning following set-up, boxes with mice and females were visually inspected every 12 hours to determine the timing of egg appearance. 48 hours later, eggs were removed from the soil and allowed to hatch in petri plates at $20^{\circ} \mathrm{C}$ containing $1.5 \%$ water agar. Egg hatch was monitored every 3 hours until no further hatching was observed.

To examine the role of soil-borne microbes on egg hatch we carried out two different experiments using a split-brood design. In the first experiment, eggs were collected from the soil from females provided with a Fresh carcass $(n=32)$. Each brood with a minimum of 20 total eggs $(n=30)$ was split into two treatment groups. Half of each brood was gently rinsed in sterile water and then allowed to hatch on sterile $1 \%$ water agar. The other half of each brood was rinsed in a solution containing the entomopathogenic bacterium Serratia marcescens at a density of $10^{8} / \mathrm{ml}$, after which eggs were placed to hatch onto sterile water agar. The splitbrood design allowed us to control for intrinsic differences in the hatch rate of broods from different females.

In the second experiment, eggs were collected from females provided with an Aged carcass. Using a splitbrood design and with the same minimum threshold for inclusion of 20 eggs $(n=29)$, broods were divided into two treatment groups. A control group of washed eggs from each family was transferred to sterile water agar. The other half of each brood was first surface sterilized in an antimicrobial solution of hen egg-white lysozyme $(1 \mathrm{mg} / \mathrm{ml})$, streptomycin $(500 \mu \mathrm{g} / \mathrm{ml})$ and ampicillin $(100 \mu \mathrm{g} / \mathrm{ml})$, and then placed onto water agar plates to hatch. Previous experiments have shown that eggs thus treated are free of bacteria [24].

To assess the ability of $N$. vespilloides eggs to withstand desiccation we collected eggs from soil 15 hours 
after females were given a carcass. This cut-off was used to ensure that eggs were roughly of the same age. Eggs were placed onto $1 \%$ sterile water agar plates and incubated for 24 hours at $20^{\circ} \mathrm{C}$. Next, eggs were transferred to glass petri dishes and allowed to hatch at $20^{\circ} \mathrm{C}$ with either $75 \%$ or $90 \%$ relative humidity (RH) in an environmental chamber. A separate set of eggs was retained on water agar as a control. The proportion of hatched eggs was scored after 3 days.

\section{Experimental infection of $N$. vespilloides eggs and larva}

To examine the capacity for eggs to mount an immune response against microbial challenge, eggs were experimentally infected with a concentrated solution of Escherichia coli and Micrococcus luteus. Eggs were collected 15 hours after females were provided with a fresh carcass and then kept at $20^{\circ} \mathrm{C}$ for 24 hours on $1 \%$ sterile water agar. Next, eggs were pricked with a sterile $1 \mathrm{mi}-$ cron tip tungsten needle (Fine Science Tools) dipped into bacterial solution (septic injury) or with a sterile needle alone (sterile injury). After infection/sterile injury, eggs were incubated for 6 hours at $20^{\circ} \mathrm{C}$ before RNA extraction. For larval infection we allowed eggs to hatch on $1 \%$ water agar. Larvae between $0-24 \mathrm{~h}$ old were then pricked with either a sterile needle or, with a needle previously dipped into the same bacterial solution as above. Larvae were incubated for 6 hours at $20^{\circ} \mathrm{C}$ before RNA extraction.

RNA extraction and real-time quantitative RT-PCR (qRT-PCR) Total RNA of 5-10 eggs or larvae was extracted using TRIzol (Invitrogen) after which the RNA was purified and DNA digested on column with the RNeasy kit (Qiagen). The quality of the RNA preparation was confirmed spectrophotometrically. One microgram of total RNA was used for cDNA synthesis. First strand cDNA was made using the Cloned AMV First Strand Synthesis kit (Invitrogen). Each qRT-PCR mixture ( $25 \mu \mathrm{l})$ contained $2.5 \mathrm{ng}$ of cDNA, and the real-time detection and analyses were done using SYBR green dye chemistry with the qPCR kit for SYBR Green I (Eurogentec) and a CFX96 thermocycler (Biorad). Thermal cycling conditions used were $50^{\circ} \mathrm{C}$ for $2 \mathrm{~min}, 95^{\circ} \mathrm{C}$ for $10 \mathrm{~min}$, then 50 cycles of $95^{\circ} \mathrm{C}$ for $15 \mathrm{~s}, 60^{\circ} \mathrm{C}$ for $30 \mathrm{~s}, 72^{\circ} \mathrm{C}$ for $30 \mathrm{~s}$. This was followed by dissociation analysis of a ramp from 65 to $95^{\circ} \mathrm{C}$ with a read every $0.5^{\circ} \mathrm{C}$. Relative quantification for each mRNA was done using the Livak-method [30]. The values obtained for each mRNA were normalized by RPL7 mRNA amount. Total RNA for each treatment was isolated twice (biological replication) and each sample was measured by qRT-PCR twice (technical replication). Comparisons between treatments (untreated, sterile injury and septic injury) were performed within one brood.
Immune-related genes and primers used for qRT-PCR

Real-time PCR oligonucleotide primers were designed using Primer3Plus (http://primer3plus.com/cgi-bin/dev/ primer3plus.cgi) by applying the rules of highest maximum efficiency and sensitivity to avoid the formation of dimers, hairpins and other artefacts. The following immune-related genes were examined: Attacin 2, Defensin 1, Defensin 2, Coleoptericin 1, Coleoptericin 2, Coleoptericin 3 and the normalizer of qRT-PCR ribosomal protein 7 (RPL7). Sequences of immune-related genes were derived from [29], and primer pairs of respective target genes were designed for qRT-PCR (Table 1).

\section{Embryo fixation and microscopy}

The extraembryonic serosa in Tribolium castaneum is known to be involved in both desiccation resistance [31] and endogenous immune competence of the eggs [15]. All insect species studied to date, with the exception of one group of higher flies [32,33], develop a serosa [34]. Embryonic development of $N$. vespilloides however, has not been studied. To examine the development of the serosa in $N$. vespilloides, fixed eggs were visualized under the confocal microscope (5x magnification). Eggs were placed onto $1 \%$ water agar plates at $20^{\circ} \mathrm{C}$ and left for 24 hours to ensure that enough time had passed to develop the serosa. Next, eggs were fixed for 18 hours at room temperature in a solution of $4 \mathrm{ml}$ phosphate buff-

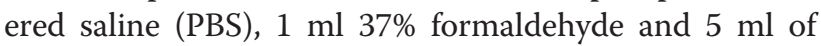
heptane. They were removed from the fixative and cut in half with a scalpel. The cut eggs were washed 3 times in PBS-Tween and then stained with DAPI for 2 hours at room temperature. After staining, the eggs were washed 3 times with PBS-T and embedded in glycerol on a glass bottom petri dish. Samples were studied with a Zeiss Cell Observer.

\section{Results}

Egg number and survival is reduced in the presence of an Aged carcass

Females that were provided with an Aged carcass laid significantly fewer eggs than females that were provided with a Fresh carcass (two-tailed Mann-Whitney U Test, $\mathrm{P}=0.012$, Figure $1 \mathrm{~A}$ ). In addition, the survival of eggs laid by females provided with an Aged carcass was significantly lower than the survival of eggs laid near a Fresh carcass (two-tailed Mann-Whitney U Test, $\mathrm{P}=0.011$, Figure $1 \mathrm{~A})$. Combining these to obtain an overall estimate of brood size, by taking the product of egg number and hatch proportion, we find that broods laid near to Fresh carcasses are significantly larger than those laid near to Old carcasses (Fresh: $32.57 \pm 3.01$ vs Old: $23.11 \pm 2.61$; two-tailed Mann-Whitney U Test, $\mathrm{P}=0.005)$. Together these data show that pre-hatch fitness is reduced by the presence of an Aged carcass. 
Table 1 Primers for immune sequences of Nicrophorus vespilloides

\begin{tabular}{|c|c|c|}
\hline Gene & Forward primer & Reverse primer \\
\hline Attacin2 & 5'-ACGTCACAGGAGAAGAGCTGA-3' & 5'-TCGGAAGGCCTGTGTGTGTA-3' \\
\hline Defensin 1 & 5'-GTCGATACGCCCATCGGTTC-3' & 5'-GCAATTGCAGACTCCGTCGA-3' \\
\hline Defensin2 & 5'-AGAGGTGCATGCGATCTGTT-3' & 5'-TGTGCCTTTGGTGTATCCGT-3' \\
\hline Coleoptericin 1 & 5'-CGAAACGGTGGTGAACAGGT-3' & 5'-TGCATTGGTTGTACCGTCGG-3' \\
\hline Coleoptericin2 & 5'-TGGTCTCCGCCGAATCCTAA-3' & 5'-GCACCTGGTCTTTCGTGCTT-3' \\
\hline Coleoptericin3 & 5'-ACTTTGGCGCGAGTCGATTT-3' & 5'-TTGATCGCCCAACTCGCTTC-3' \\
\hline RPL7 & 5'-TGCCATCAAGAAGCGCTCTG-3' & 5'-GCGCTCTTGGCTTGATGGAT-3' \\
\hline
\end{tabular}

To test the idea that bacteria in the soil cause this reduction in survival, we split broods laid near an Aged carcass and surface-sterilized one half with an antimicrobial solution while leaving the other half unsterilized. As predicted, if bacteria on the surface of eggs contributed to the failure of eggs to hatch, sterilizing eggs significantly increased egg survival when compared to washing eggs with water (paired t-test, $d f=29, p<0.001$, Figure $1 B$ ). To further examine the idea that exposure to high bacterial numbers decreases pre-hatch fitness, we again used a split-brood design and experimentally exposed eggs laid near a Fresh carcass to the soil borne entomopathogen $S$. marcescens and compared these to eggs washed in water. Exposure to $S$. marcescens had a pronounced negative effect on pre-hatch fitness (paired t-test, $\mathrm{df}=28$, $\mathrm{p}<0.001$, Figure $1 C$ ). Notably, the reduction in survival following experimental infection, and the increase in survival following surface sterilization are roughly equivalent. Furthermore, these differences are similar to the differences first observed in untreated eggs laid near Aged and Fresh carcasses. Together, these data strongly indicate that harmful bacteria in the environment of Aged carcasses significantly reduce pre-hatch fitness.
Antimicrobial peptide expression in response to infection Although survival of $N$. vespilloides eggs is reduced in the presence of an Aged carcass, overall egg viability is still quite high; approximately $70 \%$ of the eggs still survive even under these challenging conditions (Figure 1A). As we have previously shown that the eggs of Tribolium castaneum can induce antimicrobial peptide genes upon infection [15], induction of antimicrobial peptides might also increase survival in adverse conditions for the eggs of $N$. vespilloides. We measured gene expression of several antimicrobial peptides after both sterile injury and septic injury in $N$. vespilloides eggs and larva. Surprisingly, in eggs we found marginal, if any, upregulation of antimicrobial peptide genes after infection (Figure 2). Only one gene (coleoptericin 2, Figure 2E) was induced over 10 fold after infection. By contrast, freshly emerged larvae show clear induction of all antimicrobial peptide genes tested (Figure 2). To verify that mRNA levels are lower in the eggs, we compared infected eggs with infected larvae. As expected, transcript levels are higher in larvae (Additional file 1: Figure S1). These data show that although freshly emerged larvae can induce immune genes upon infection,
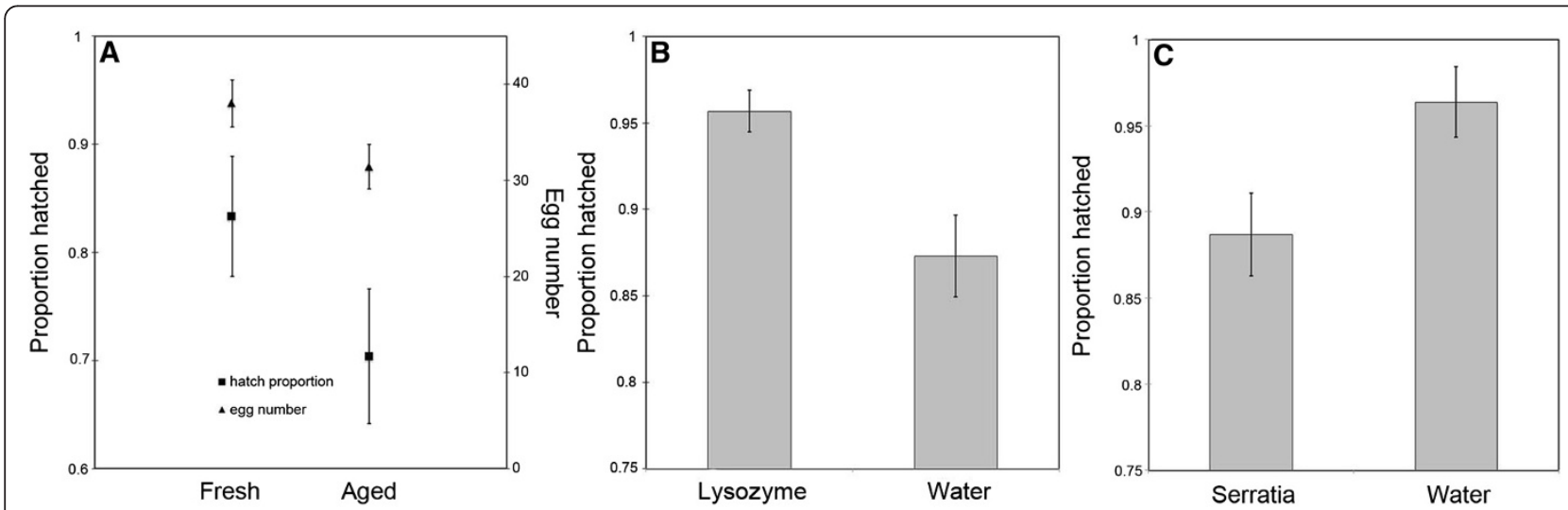

Figure 1 Egg survival and number under different treatments. A) Both egg number and egg survival are significantly lower when in the presence of an Aged carcass. B) Eggs collected from an Aged carcass show increased survival when sterilized, indicating the negative effect of high bacterial numbers surrounding Aged carcasses. C) Eggs collected from a Fresh carcass show decreased survival when experimentally exposed to the entomopathogenic bacterium S. marcescens. 


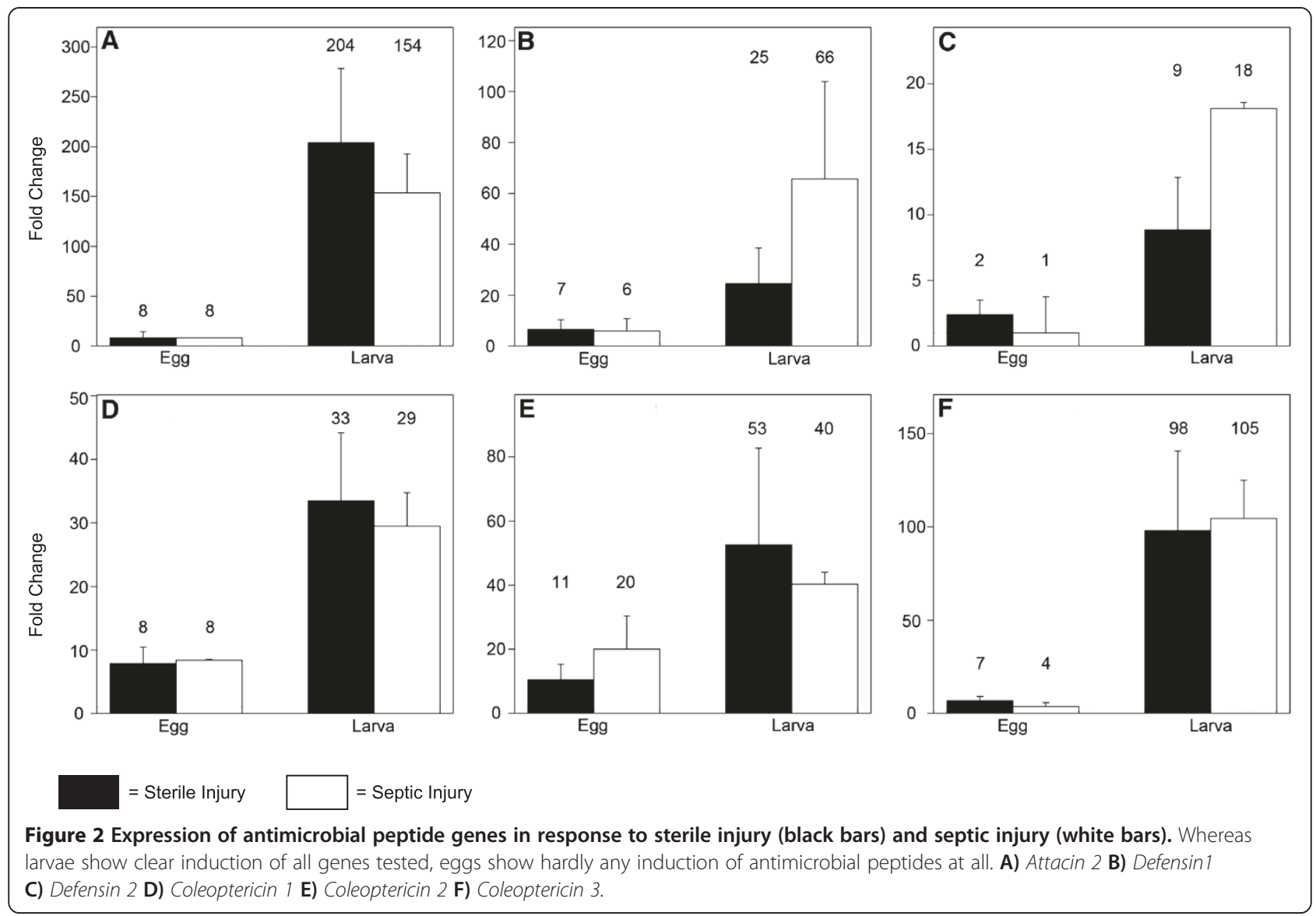

eggs of $N$. vespilloides show very limited AMP inducing capacities.

\section{Eggs develop an extraembryonic serosa}

The immune response of Tribolium castaneum eggs depends on the presence of an extraembryonic epithelium called the serosa [15]. By contrast, the immune response is poor in eggs of the fruit fly Drosophila melanogaster which lack this epithelium. Given the apparent absence of endogenous egg immunity in $N$. vespilloides, we hypothesized that this species, like Drosophila, would lack a serosal epithelium. We tested this idea in two ways, first by measuring desiccation tolerance of eggs, as the serosa imparts drought resistance in T. castaneum [31], and second by directly examining DAPI stained eggs via confocal microscopy. $N$. vespilloides eggs are highly susceptible to desiccation; egg survival dropped from $92 \%$ at $90 \% \mathrm{RH}$ to $0 \%$ at $75 \% \mathrm{RH}$ (chi-square test, $\mathrm{p}<0.001$ ). Although this result, together with the absence of endogenous immunity is consistent with the absence of a serosal epithelium, DAPI-stained confocal microscopy clearly revealed an epithelium around the egg (Figure 3A). This epithelium could easily be distinguished from the amnion in optical sections (Figure 3B) and was identified as serosa.

\section{Discussion}

Nicrophorus eggs are deposited into the soil in close proximity to vertebrate carcasses [17]. Eggs in this grave-soil environment are exposed to increased nutrient fluxes from carcass decay that increases the biomass of endogenous bacteria and of bacteria that migrate to the soil from the perforated carcass [35]. Several previous studies have documented the diverse and persistent negative effects of this flora on the survival and growth of developing larvae $[16,27,28,36]$. Here we extend these findings by showing that carcass associated bacteria also significantly reduce the survival of Nicrophorus eggs. We found that females provided with an Aged carcass laid fewer eggs that were less likely to hatch than their female counterparts provided with a Fresh carcass (Figure 1A). In addition, we show that egg hatching success is a direct function of bacterial exposure; eggs washed free of surface-associated bacteria show increased survival compared to unwashed eggs (Figure 1B) while eggs washed in a bacterial solution show decreased survival compared to unexposed eggs (Figure 1C). The overall consequence of this exposure is an approximate $30 \%$ decline in potential brood size. This cost, in addition to those already identified at later stages of beetle development, clarify the risks to 


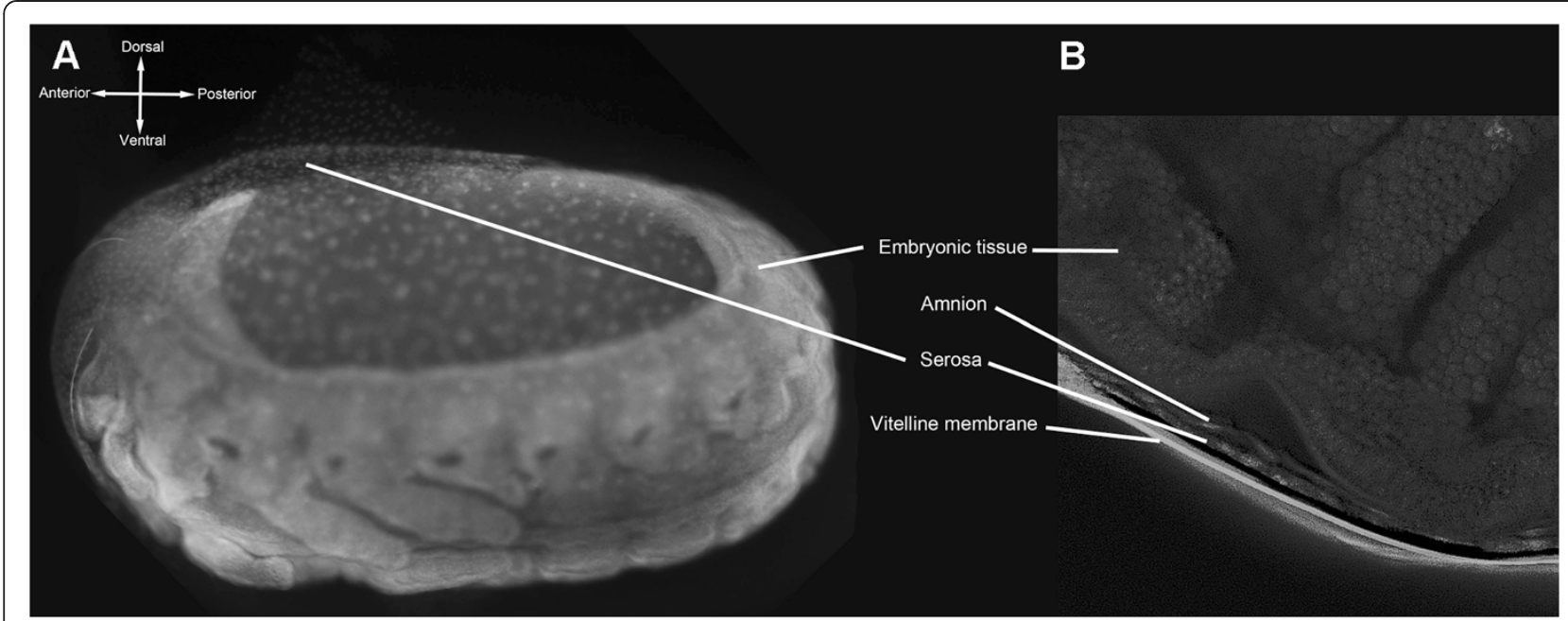

Figure 3 The eggs of $\boldsymbol{N}$. vespilloides develop an extraembryonic serosa. A) Overview of a complete embryo, the developing head is visible at the anterior. The serosal epithelium can be clearly seen just above the head. B) Optical section of an N. vespilloides egg. The embryo, serosa, amnion and vitelline membrane can be clearly distinguished.

Nicrophorus of rearing young on microbe-rich contaminated carcasses.

The carcasses that Nicrophorus larvae rely upon are classical bonanza resources that are unpredictable in time and space. Parents modify the carcass in numerous ways that increase larval growth and survival. The carcass is buried, stripped of fur and coated with both antibacterial and antifungal compounds [20,22,23,27,37]. In addition, parents defend the carcass before and following the arrival of larvae from insect competitors like flies or other carrion beetles $[16,17,38]$. In contrast to these elaborate behaviours used to defend larvae, there is surprisingly little direct evidence for parental defence of eggs. Earlier research failed to find any lysozyme-like activity inside or on the $N$. vespilloides egg [24], suggesting an absence of direct antimicrobial provisioning. And although antiseptic volatiles secreted by parents into the soil surrounding the carcass may provide an indirect benefit to eggs, this is as yet untested [37].

Why is egg defence apparently missing in this species? One possible explanation is that explicit care of eggs trades-off with carcass maintenance and defence. Thus rather than investing in individual eggs, parents instead invest in preserving the resource that will provide an aggregate benefit to any larvae that survive the eggstage and eventually migrate to the carcass. Consistent with this idea, egg production in Nicrophorus does not appear to engender significant costs [39], the number of eggs observed in experimental Nicrophorus broods typically exceeds the number of larvae found on the carcass and infanticidal culling is common [40,41]. It is likely that there is further mortality in the field where eggs face additional predation risks that are not present in the lab. Finally, by secreting antimicrobials on the carcass surface, parents can maintain the carcass in a suitable state for extended time periods, assuming it is found prior to significant decomposition. Also, because parents prefer a Fresh over an Aged carcass [16], eggs may not have been selected to be able to cope with high levels of associated bacteria on extensively decomposed carrion.

A second possibility is that explicit defence is prohibitively expensive, especially when, even in its absence, egg survival is quite high (Figure 1C). This contrasts markedly with other species, like earwigs, where untended eggs challenged with mold infection show far more dramatic declines in hatch success [42]. Although we do not know the cause for high rates of intrinsic survival, it is possible that this is facilitated by the barrier defence provided by the extraembryonic serosa (Figure 3). If so, this would be consistent with an immune-related function for the Nicrophorus serosa, even if the serosa in this species appears not to extensively regulate endogenous AMP production as it does for eggs of Tribolium castaneum. A challenge for future studies is to explicitly test this hypothesis using RNAi based targeted knock-downs of the developmental genes that regulate the production of this extraembryonic tissue.

Even in the absence of parental protection, eggs of some insects retain the capacity to generate an endogenous immune response against pathogen challenge $[9,14,15]$; this is thought to be one important cause for the low incidence of parental care in insects $[43,44]$. Yet this endogenous response is absent in $N$. vespilloides. In that respect, there are striking similarities in development beween $N$. vespilloides and D. melanogaster. 
Both species lack inducible egg immunity and develop on ephemeral resources that favour rapid development times $[15,17,45]$, and specifically rapid embryonic development. Embryonic development in Nicrophorus is approximately 3-6 times faster than Tribolium and Manduca $[46,47]$, and about 20 hours faster than Aedes, which are known to go into diapause, meaning they have to survive for a long time until the conditions favour hatching [48]. By contrast, Nicrophorus develop in the presence of a highly valuable and decaying resource; individuals need to hatch, feed and disperse before the carcass is either claimed by another animal or becomes unsuitable for development. This strong selection for fast development might be reflected by a trade-off between a well-protected but slow developing egg and a fast-developing but less protected egg. Similar tradeoffs between growth and immune competence are known from plants [49], birds [50] and insects [51,52]. Although additional experiments are needed to confirm the relation between rapid development and the lack of immune competence in insect eggs, the high survival and poor immune competence of both $N$. vespilloides and D. melanogaster eggs under normal conditions suggests that fast development is obtained at the expense of immune competence.

\section{Conclusions}

Our work builds upon previous studies demonstrating the profound costs to $N$. vespilloides from rearing their offspring in the presence of microbial competitors or pathogens in the soil environment. Although parental care in this species can serve to mitigate some of these risks, our data suggest that at least direct care does not extend to eggs. The indirect effects of fumigation with volatiles of the surrounding microhabitat might be important, however this conjecture requires further testing. The lack of direct parental provisioning of eggs may result from a trade-off between egg protection and carcass maintenance. Similarly, the lack of immune competence may be caused by a trade-off between immunity and the need for rapid growth on a rich and ephemeral resource. Although similar life-history trade-offs are known in a broad range of species, we are unaware of results showing this trade-off for eggs. This result therefore has broad implications owing to the obvious importance of egg survival for lifetime reproductive success, and suggests the need to investigate the development of immune competence more broadly as a function of developmental timing.

\section{Data accessibility}

All data used in this manuscript are present in the manuscript and its supporting information.

\section{Additional file}

Additional file 1: Figure S1. Expression differences between infected eggs and infected larvae. Expression of antimicrobial peptides in general is significantly higher in larvae than in eggs. Only the difference in Defensin 2 was small, which is expected as it is the least induced antimicrobial peptide in this study.

\section{Competing interests}

The authors declare that they have no competing interests.

\section{Authors' contributions}

DER, CGCJ and YW conceived of the study. YW and CGCJ carried out all experimental work on survival, desiccation resistance, response to infection and qRT-PCR. HV and AV designed primers for qRT-PCR. CGCJ and MVDZ performed the microscopy. YW, CGCJ and DER wrote the initial draft of the paper. DER, CGCJ, YW, HV, MVDZ and AV analysed and discussed data and their interpretation, and helped draft the final manuscript. All authors read and approved the final manuscript.

\section{Acknowledgements}

This work was supported by start-up funds from the University of Leiden to DER. YW was supported by a graduate fellowship from the China Scientific Council (CSC).

\section{Author details}

${ }^{1}$ Institute of Biology Leiden, Leiden University, Sylviusweg 72, 2333 Leiden, $\mathrm{BE}$, the Netherlands. ${ }^{2}$ Department of Entomology, Max Planck Institute for Chemical Ecology, Hans-Knöll-Straße 8, D-07745 Jena, Germany. ${ }^{3}$ Justus-Liebig University, Heinrich-Buff-Ring 26-32, D-35392 Giessen, Germany.

Received: 7 July 2014 Accepted: 22 September 2014 Published online: 27 September 2014

\section{References}

1. Brock PM, Murdock CC, Martin LB: The history of ecoimmunology and its integration with disease ecology. Integr Comp Biol 2014, 54(3):353-362.

2. Delves PJ, Martin SJ, Burton DR: Essentials : Roitt's Essential Immunology (12th Edition). Hoboken, NJ, USA: Wiley-Blackwell; 2011.

3. King AE, Paltoo A, Kelly RW, Sallenave JM, Bocking AD, Challis JRG: Expression of natural antimicrobials by human placenta and fetal membranes. Placenta 2007, 28(2-3):161-169.

4. Rolff J, Reynolds SE: Insect Infection and Immunity; Evolution, Ecology and Mechanisms. Oxford, UK: Oxford University Press; 2009.

5. Hasselquist D, Nilsson J-Å: Maternal transfer of antibodies in vertebrates: trans-generational effects on offspring immunity. Philos Trans $R$ Soc B Biol Sci 2009, 364(1513):51-60.

6. D'Alba L, Shawkey M, Korsten P, Vedder O, Kingma S, Komdeur J, Beissinger S: Differential deposition of antimicrobial proteins in blue tit (Cyanistes caeruleus) clutches by laying order and male attractiveness. Behav Ecol Sociobiol 2010, 64(6):1037-1045.

7. Hathaway JJ, Adema CM, Stout BA, Mobarak CD, Loker ES: Identification of protein components of egg masses indicates parental investment in immunoprotection of offspring by Biomphalaria glabrata (gastropoda, mollusca). Dev Comp Immunol 2010, 34(4):425-435.

8. Trauer U, Hilker M: Parental legacy in insects: variation of transgenerational immune priming during offspring development. PLoS One 2013, 8(5):e63392.

9. Freitak D, Schmidtberg H, Dickel F, Lochnit G, Vogel H, Vilcinskas A: The maternal transfer of bacteria can mediate trans-generational immune priming in insects. Virulence 2014, 5(4):547-554.

10. Zanchi C, Troussard JP, Moreau J, Moret Y: Relationship between maternal transfer of immunity and mother fecundity in an insect. Proc Bio/ Sci 2012, 279(1741):3223-3230.

11. Hernández López J, Schuehly W, Crailsheim K, Riessberger-Gallé U: Trans-generational immune priming in honeybees. Proc Biol Sci 2014, 281(1785):20140454.

12. Moreau J, Martinaud G, Troussard J-P, Zanchi C, Moret Y: Trans-generational immune priming is constrained by the maternal immune response in an insect. Oikos 2012, 121(11):1828-1832. 
13. Roth O, Joop G, Eggert H, Hilbert J, Daniel J, Schmid-Hempel P, Kurtz J: Paternally derived immune priming for offspring in the red flour beetle, Tribolium castaneum. J Animal Ecol 2010, 79(2):403-413.

14. Gorman MJ, Kankanala P, Kanost MR: Bacterial challenge stimulates innate immune responses in extra-embryonic tissues of tobacco hornworm eggs. Insect Mol Biol 2004, 13(1):19-24.

15. Jacobs CGC, van der Zee M: Immune competence in insect eggs depends on the extraembryonic serosa. Dev Comp Immunol 2013, 41(2):263-269.

16. Rozen DE, Engelmoer DJP, Smiseth PT: Antimicrobial strategies in burying beetles breeding on carrion. Proc Natl Acad Sci 2008, 105(46):17890-17895.

17. Scott MP: The ecology and behavior of burying beetles. Annu Rev Entomol 1998, 43(1):595-618.

18. Smiseth PT, Ward RJS, Moore AJ: Asynchronous hatching in Nicrophorus vespilloides, an insect in which parents provide food for their offspring. Funct Ecol 2006, 20(1):151-156

19. Lock JE, Smiseth PT, Moore AJ: Selection, inheritance, and the evolution of parent-offspring interactions. Am Nat 2004, 164(1):13-24.

20. Arce AN, Johnston PR, Smiseth PT, Rozen DE: Mechanisms and fitness effects of antibacterial defences in a carrion beetle. J Evol Biol 2012, 25(5):930-937

21. Reavey CE, Warnock ND, Vogel H, Cotter SC: Trade-offs between personal immunity and reproduction in the burying beetle, Nicrophorus vespilloides. Behav Ecol 2014, doi:10.1093/beheco/art127.

22. Hall CL, Wadsworth NK, Howard DR, Jennings EM, Farrell LD, Magnuson TS, Smith RJ: Inhibition of microorganisms on a carrion breeding resource: the antimicrobial peptide activity of burying beetle (Coleoptera: Silphidae) oral and anal secretions. Environ Entomol 2011, 40(3):669-678.

23. Cotter SC, Kilner RM: Sexual division of antibacterial resource defence in breeding burying beetles, Nicrophorus vespilloides. J Animal Ecol 2010, 79(1):35-43.

24. Arce AN, Smiseth PT, Rozen DE: Antimicrobial secretions and social immunity in larval burying beetles, Nicrophorus vespilloides. Animal Behaviour 2013, 86(4):741-745.

25. Reavey CE, Beare L, Cotter SC: Parental care influences social immunity in burying beetle larvae. Ecol Entomol 2014, 39(3):395-398.

26. Urbański A, Czarniewska E, Baraniak E, Rosiński G: Developmental changes in cellular and humoral responses of the burying beetle Nicrophorus vespilloides (Coleoptera, Silphidae). J Insect Physiol 2014, 60:98-103.

27. Cotter SC, Topham E, Price AJP, Kilner RM: Fitness costs associated with mounting a social immune response. Ecol Lett 2010, 13(9):1114-1123.

28. Steiger S, Gershman SN, Pettinger AM, Eggert A-K, Sakaluk SK: Sex differences in immunity and rapid upregulation of immune defence during parental care in the burying beetle, Nicrophorus orbicollis. Functional Ecology 2011, 25(6):1368-1378

29. Vogel H, Badapanda C, Vilcinskas A: Identification of immunity-related genes in the burying beetle Nicrophorus vespilloides by suppression subtractive hybridization. Insect Mol Biol 2011, 20(6):787-800.

30. Livak KJ, Schmittgen TD: Analysis of relative gene expression data using real-time quantitative PCR and the 2(-Delta Delta C(T)) Method. Methods 2001, 25(4):402-408.

31. Jacobs CGC, Rezende GL, Lamers GEM, Van Der Zee M: The extraembryonic serosa protects the insect egg against desiccation. Proc Biol Sci 2013, 280(1764):20131082.

32. Rafiqi AM, Lemke S, Ferguson S, Stauber M, Schmidt-Ott U: Evolutionary origin of the amnioserosa in cyclorrhaphan flies correlates with spatial and temporal expression changes of zen. Proc Natl Acad Sci U S A 2008, 105(1):234-239.

33. Schmidt-Ott $\mathrm{U}$ : The amnioserosa is an apomorphic character of cyclorrhaphan flies. Dev Genes Evol 2000, 210(7):373-376.

34. Roth S: Gastrulation in other insects. In Gastrulation: From Cells to Embryos. Cold Spring Harbor: Cold Spring Harbor Laboratory Press; 2004:105-121.

35. Carter DO, Yellowlees D, Tibbett M: Cadaver decomposition in terrestrial ecosystems. Naturwissenschaften 2007, 94(1):12-24

36. McLean AHC, Arce AN, Smiseth PT, Rozen DE: Late-life and intergenerational effects of larval exposure to microbial competitors in the burying beetle Nicrophorus vespilloides. J Evol Bio/ 2014, 27(6):1205-1216.

37. Degenkolb T, During RA, Vilcinskas A: Secondary metabolites released by the burying beetle Nicrophorus vespilloides: chemical analyses and possible ecological functions. J Chem Ecol 2011, 37(7):724-735

38. Wilson DS, Fudge J: Burying beetles: intraspecific interactions and reproductive success in the field. Ecol Entomol 1984, 9(2):195-203.
39. Ward RJS, Cotter SC, Kilner RM: Current brood size and residua reproductive value predict offspring desertion in the burying beetle Nicrophorus vespilloides. Behav Ecol 2009, 20(6):1274-1281.

40. Trumbo ST: Regulation of brood size in a burying beetle, nicrophorustomentosus (SILPHIDAE). J Insect Behavior 1990, 3(4):491-500

41. Trumbo ST, Fernandez AG: Regulation of brood size by male parents and cues employed to assess resource size by burying beetles. Ethol Ecol Evol 1995, 7(4):313-322.

42. Boos S, Meunier J, Pichon S, Kölliker M: Maternal care provides antifungal protection to eggs in the European earwig. Behav Ecol 2014, 25(4):754-761.

43. Zeh DW, Zeh JA, Smith RL: Ovipositors, Amnions and eggshell architecture in the diversification of terrestrial arthropods. Q Rev Biol 1989, 64(2):147-168.

44. Royle NJ, Smiseth PT, Kölliker M: The Evolution of Parental Care. Oxford: Oxford University Press; 2012

45. Abasa RO: Effects of temperature, relative humidity, lipid and water content on post-oviposition development of eggs of Stomoxys calcitrans. Entomol Exp Appl 1983, 33(3):259-262

46. Howe RW: The effect of temperature and humidity on the rate of development and mortality of Tribolium Castaneum (Herbst) (Coleoptera, Tenebrionidae). Ann Appl Biol 1956, 44(2):356-368.

47. Kingsolver JG, Nagle A: Evolutionary divergence in thermal sensitivity and diapause of field and laboratory populations of manduca sexta. Physiol Biochem Zool 2007, 80(5):473-479.

48. Urbanski JM, Benoit JB, Michaud MR, Denlinger DL, Armbruster P: The molecular physiology of increased egg desiccation resistance during diapause in the invasive mosquito, Aedes albopictus. Proc Biol Sci 2010, 277(1694):2683-2692

49. Lozano-Durán R, Macho AP, Boutrot F, Segonzac C, Somssich IE, Zipfel C, Nürnberger T: The transcriptional regulator BZR1 mediates trade-off between plant innate immunity and growth. elife 2013, 2:e00983.

50. Brommer JE: Immunocompetence and its costs during development: an experimental study in blue tit nestlings. Proc Biol Sci 2004, 271:S110-S113.

51. Siva-Jothy MT, Moret Y, Rolff J: Insect Immunity: An Evolutionary Ecology Perspective. In Advances in Insect Physiology. 32nd edition. Edited by Simpson SJ. London, UK: Academic Press; 2005:1-48.

52. Diamond SE, Kingsolver JG: Host plant quality, selection history and trade-offs shape the immune responses of Manduca sexta. Proc Biol Sci 2011, 278(1703):289-297.

doi:10.1186/s12862-014-0208-x

Cite this article as: Jacobs et al.: Egg survival is reduced by grave-soil microbes in the carrion beetle, Nicrophorus vespilloides. BMC Evolutionary Biology 2014 14:208.

\section{Submit your next manuscript to BioMed Central and take full advantage of:}

- Convenient online submission

- Thorough peer review

- No space constraints or color figure charges

- Immediate publication on acceptance

- Inclusion in PubMed, CAS, Scopus and Google Scholar

- Research which is freely available for redistribution 